11. Varlamov, D. I. (2013). Artikuliatsiia v dirizhirovanii. Orkestr, 1-2, 14-16.

12. Dmitriev, L. B. (1968). Osnovy vokalnoi pedagogiki. Moscow: Muzyka, 674.

13. Tsiatsiun, S. (2018). Step-by-step methodology of the musical and listening culture of adolescents by means of multimedia. Scientific Bulletin of Mukachevo State University Series "Pedagogy and Psychology", 1 (7), 154-156. doi: http://doi.org/10.31339/2413-3329-2018-1(7)-154-156

14. Galleev, B. (2006). Iskusstvo v pole tiagoteniia. Saratov: SGK im. L. V. Sobinova, 48-49.

Received date 06.10.2020

Accepted date 24.11.2020

Published date 25.12.2020

Anna Kyfenko, PhD, Lecturer, Applied College «Universum» Borys Grinchenko Kyiv University, Yu. Haharina ave, 16, Kyiv, Ukraine, 02094

E-mail: a.kifenko@gmail.com

Tetyana Romanova, Specialist of Highest Category, Lecturer-Methodologist, Applied College «Universum» Borys Grinchenko Kyiv University, Yu. Haharina ave, 16, Kyiv, Ukraine, 02094

UDC 378:37.[013.42+37.013.43]

DOI: $10.15587 / 2519-4984.2020 .217194$

\title{
THE ESSENCE OF EXPERIMENTAL RESEARCH OF THE PROCESS OF STUDENTS' SOCIOCULTURAL VALUES FORMATION IN THE EDUCATIONAL ENVIRONMENT OF HIGHER EDUCATION INSTITUTIONS
}

\section{E. Zaredinova}

The relevance of the problem of students' sociocultural values formation in the educational environment of higher education institutions is obtained in the article. The theoretical substantiation of the problem is carried out and the necessity and expediency of revealing the essence and logic of experimental research of the process of students' sociocultural values formation in the educational environment of higher educational institutions is proved. The methodological basis of the research, which is represented by the polyparadigmal integrity of educational paradigms and the synthesis of ideas of scientific approaches, and the research methods, used in the work, are disclosed. It has been found, that the essence of the experimental work is to verify the potential of the methodology of students' sociocultural values formation within the axio-oriented educational environment of higher education institutions and clarify the logic of the axiogenesis of sociocultural values. The criteria apparatus of the research is revealed, it contains motivationalaxiological, cognitive-reflexive, and subject-activity criteria with corresponding indicators. In accordance with the requirements for the diagnostic stage of the experimental study, the diagnostic tools, which used in the ascertaining and control stages of the experimental work, containing both standardized approaches ("Value Orientations Study" approach by P. Stepanov); “Schwartz's Study of Personality Values” questionnaire, etc.), and author's proprietary questionnaires ("Level of Formation of Sociocultural Values According to the Motivational-axiological Criterion" questionnaire etc.), are presented. The general sequence of experimental work, which was reduced to such a logical scheme, is highlighted: 1) diagnostics of level of sociocultural values formation; 2) the methodology of students' sociocultural values formation in the educational environment of a higher education institution; 3) analysis of the dynamics of sociocultural values at different stages of its axiogenesis and environment. The summary interpretation of criteria, indicators, and related diagnostic approaches is presented in the table. The stages of experimental work are succinctly disclosed

Keywords: sociocultural values, axiogenesis, verification of research results, research methods, diagnostic tools

Copyright (C) 2020, E. Zaredinova. This is an open access article under the CC BY license (http://creativecommons.org/licenses/by/4.0).

\section{Introduction}

Modern globalization and European integration processes, the rapid pace of society emphasize the importance of sociocultural values in human life because they determine the identity of a culture that distinguishes it from others, as well as the mentality, inherent in this culture, and the uniqueness of its cultural and historical experience. Thus, sociocultural values unite the sociocultural traditions of a certain society, the social aspects of different ethnic groups and individuals. It is already wellestablished in science, that the value sphere of the individual is its fundamental, basic component (A. Asmolov, 
I. Bekh, D. Leontiev), which acquires special importance in times of social change, because values are the regulator of consciousness and motivator of behavior. The special social group is students, distinguished from other groups by "high educational level, high cognitive motivation, the highest social activity and a very harmonious combination of intellectual and social maturity" [1], which gives reason to consider students sensitive to the formation and internalization of sociocultural values of individual. Thus, the outlined objective circumstances determine the need for experimental research of the process of formation of sociocultural values of students in the educational environment of higher education institutions (hereinafter - HEI).

\section{Literature review}

It is stated, that in psychology the study of sociocultural and value issues is presented in the format of well-known psychological theories, namely: cultural-historical theory (L. Vygotsky) [2]; semantic concept (D. Leontiev) [3]; axiological psychology of personality (Z. Karpenko, T. Severina, V. Mytsko, G. Radchuk) [4-6]; concepts of values and value orientations (M. Rokich), cultural value orientations (S. Schwartz) [7].

In pedagogical science the phenomenon of sociocultural values is interpreted in connection with the concepts of education, training, upbringing, personality formation and considered in several directions, namely: research of sociocultural values within the new scientific direction - axiopedagogy, the object of which is the peculiarities of the genesis, functioning and formation of the value-semantic sphere of the teacher in the process of professional training; subject (M. Yanyts'kyy, A. Seryy, $\mathrm{Yu}$. Pelekh) is the study of the prerequisites and factors of formation of the value-semantic sphere, its content, structure and features, patterns, stages and levels of formation (M. Yanyts'kyy, A. Seryy, Yu. Pelekh) [8].

In previous works we have considered the conceptual foundations of the process of formation of sociocultural values of HEI students, based on the synthesis of ideas of personality-oriented, semantic and reflective educational paradigms and provisions of sociocultural, systemic, acmeological, activity, subjective, competency, and environmental scientific approaches. It was proved, that these paradigms and scientific approaches are concretized in strategic (axiological orientation of education; cultural and historical determination of education; anthropocentrism; systematicity and consistency in the formation of the axiosphere of personality; phasing and transformation of values from lower to higher; connection of personal axiogenesis with professiogenesis; environmental orientation) and tactical (modeling of content, forms and methods of formation of sociocultural values; activity; interactivity and partnership; task-situational intenseness; technologization) principles of formation of student's sociocultural values.

The content aspects of the research on the method of formation of sociocultural values are connected with their structure, which contains motivational-value (value attitude to cultures and traditions of other peoples and representatives of ethnic and social groups; need to understand psyche and mentality of Ukrainian people; mo- tive of identity and feeling of belongingness to the Ukrainian nation, value attitude to the future profession, value attitude to oneself, critical self-perception, adequate self-esteem); cognitive (knowledge of culture and traditions of other peoples; knowledge of basic values of modern Ukrainian society; knowledge of the essence of patriotic values; knowledge of the basic values of the future profession; knowledge of one's «I $»$ as an individual, awareness on one's own actions and relationships; knowledge of the inner world of another person, knowledge of the determinants of behavior and attitudes of others) and praxiological (experience on the implementation of value attitude to cultures and traditions of other peoples and social groups; realization of selfidentity and sense of belonging to the Ukrainian nation; ability to implement value attitude to future profession during the educational process in HEI; ability to conduct self-analysis of one's own value sphere, actions and attitudes; ability to build partnerships with other people on the basis of "subject-subject interaction") components, each of which in accordance with the leading types of sociocultural values provides the aspect of sociocultural macro-values, sociocultural meso-values, sociocultural micro-values. The procedural component of the outlined model is based on the logic of axiogenesis of sociocultural values and is related to the process of axio-oriented environment formation. In a concentrated form, the outlined basic theoretical positions of the study are presented in the appropriate model [9].

However, without diminishing the importance of the outlined theoretical work and taking into account the essence of the dialectical principle of connection of theory with practice, we should note that theoretical developments cannot be complete, if they do not provide feedback, namely: control and evaluation of results and their comparison with the expected results. That is, the expediency of experimental verification of the effectiveness, scientific and practical significance of the method of forming sociocultural values of students is obvious.

\section{The aim and objectives of the study}

The purpose of the article is to reveal the essence and logic of the experimental study of the process of formation of sociocultural values of students in the educational environment of HEI. been set:

To accomplish the aim, the following tasks have

1) to identify the criteria apparatus and diagnostic tools for the experimental research;

2) to determine the stages of the experimental work, reflecting the logic of diagnostics of the level of formation of sociocultural values and axiogenesis of students;

3) to provide an analysis of the results of the control stage of the experiment.

\section{Methodology and research methods}

The methodological basis of the study is represented by the polyparadigmatic integrity of personalityoriented, semantic and reflexive educational paradigms and, according to the levels of methodology, polyapproach synthesis of culturological, axiological (philosophical level); sociocultural, systemic, acmeological, 
activity (general scientific level); subjective, competence (specific scientific level); technological, environmental (methodological or technological level) scientific approaches. The study used empirical methods: observation, survey, questionnaire, expert assessment and selfassessment, testing; pedagogical experiment, aimed at determination of the effectiveness of methods of forming sociocultural values of students in the educational environment of HEI; methods of mathematical statistics: nonparametric Pearson test $(\chi 2)$ and parametric Student's t-test, $\lambda-$ Kolmogorov-Smirnov test, nonparametric Mann-Whitney U-test - for quantitative and qualitative processing of pedagogical experiment results, determination of statistical significance of the results, obtained during the experiment.

\section{Result}

In the format of the presented research, the essence of the experimental work is to verify the potential of the methodology of formation of sociocultural values of students within the axio-oriented educational environment of HEI and to clarify the logic of axiogenesis of sociocultural values.

Thus, in the process of experimental work, the leading provisions of the theory and methods of formation of sociocultural values, as well as the model of the outlined process were subject to verification.

It should be noted, that the experimental study was preceded by a preparatory stage, within which a number of significant theoretical and methodological provisions were substantiated, which became thorough for further experimental work. Let's introduce them.

1. Sociocultural values are specific to the concept of "value", as well as a synthetic, integrative cohesiveness of the concepts of society, culture and values.

2. Sociocultural values are the basic life meanings of a person in everyday life, in relation to the surrounding reality, in which models of social behavior and features of a certain culture are reflected.

3. Axiogenesis of sociocultural values of individual is a process of their successive transformations, associated with the progressive transition of values from lower to higher levels; with the transformation of some values into others.

4. The environment formation is an organized, purposeful process of creating an axio-oriented educational environment as a plane of formation of sociocultural values in students.

5. The logic and dynamics of the environment formation corresponds to the stages of axiogenesis and such characteristics of the educational environment as immersion (the illusion of presence and interaction with the environment approaching the real one); presence (psychological state of perceiving oneself in one place of the environment, physically being in another); interactivity (activity of users of the environment, mobility of the form of the environment and its content).

An important stage of the study is the development of the criterion apparatus, determining the level of formation of sociocultural values of students. At the same time, it was thorough to understand the criterion as a feature that determines the level of formation of sociocultural values, and the indicator as a component of the criterion that reveals the essence and features of sociocultural values of HEI students. Significant in solving this research task was compliance with certain requirements for the criteria, namely:

1) additivity - which involves the application of the criterion to the components of a particular phenomenon, the summation of its individual results;

2) adequacy - as compliance with the studied phenomenon both in the context of its nature and in the dynamics of its changes;

3) quantitativeness - the criterion should be numerical; the same actual values of different phenomena when applying the criterion should give the same numerical values of the measured values [10].

In addition, the criterion apparatus of the study is determined by the structure of sociocultural values. Note that the motivational-value component of sociocultural values corresponds to the motivational-axiological criterion, cognitive component to the cognitive-reflexive criterion, praxiological component to the subject-activity criterion.

Motivational-axiological criterion reflects the level of formation of motives, needs, value based attitudes to the world in modern conditions of globalization and cultural heterogeneity of society, to cultures and traditions of other peoples, to mentality and psyche of Ukrainian people, to the Homeland, to the future profession, to themselves and others.

Cognitive-reflexive criterion characterizes the formation of axiological knowledge and different ideas in the context of sociocultural values and is associated with such characteristics as relevance, diversity, depth, flexibility, articulation, effectiveness.

The subject-activity criterion is related to the acquisition of value experience, actions, and patterns of behavior of students in accordance with their sociocultural values, as well as the willingness to learn and produce sociocultural values in the process of motivated activity on the basis of personal agency.

An important stage of the research work was the selection of methods, corresponding to the outlined criteria that perform diagnostic functions. It is essential, that in the development of diagnostic tools we were based on the requirements for the diagnostic stage of experimental research, and which lie in the following: the diagnostic complex should include a selection of tasks, adequate to the real pedagogical process of the educational institution; this complex should be instructed in the logic of goals and sequence of solving the whole hierarchy of pedagogical tasks according to the real process of the educational institution (with the extraction, if necessary, of certain groups of functional class tasks - gnostic, constructive, etc.); the application of the diagnostic set of tasks should take place in conditions as close as possible to the situations of the natural pedagogical process of the educational institution (such as problematicity; mobility of all components; variability; complexity; polymorphism; parallel branching of goals, etc.) and real pedagogical work; complex diagnostic methods should be constructive, suitable for different conditions (HEI, school, pre-school educational facility, etc.) and assume the possibility of replacing some of its elements with others; the diagnostic complex must involve the use of 
mathematical methods of analysis; this complex should include a system of reference samples to identify the results of the solution.

It should be noted, that the diagnostic tools, used in the process of summative and control stages of the experimental work, contain both standardized methods and author's questionnaires, developed on the basis of theoretical analysis of scientific papers, related to the research problem and data, obtained as a result of conversations with students and observations. A summary of the criteria, indicators and relevant diagnostic methods is presented in Table 1.

Criteria, indicators and methods of measuring sociocultural values

Table 1

\begin{tabular}{|c|}
\hline Criteria / indicators \\
\hline 1 \\
\hline $\begin{array}{l}\text { Motivational-axiological criterion: } \\
\text { Indicators: }\end{array}$ \\
\hline $\begin{array}{l}\text { - values to the cultures and traditions of other peo- } \\
\text { ples and representatives of ethnic and social groups; } \\
\text { - the need for communication and interaction with } \\
\text { representatives of other nationalities on the basis of } \\
\text { interethnic, intercultural tolerance; }\end{array}$ \\
\hline $\begin{array}{l}\text { - motivation to realize the mentality and psyche of } \\
\text { the Ukrainian people; } \\
\text { - motives, related to the study of cultural heritage } \\
\text { and traditions of the Ukrainian people; }\end{array}$ \\
\hline $\begin{array}{l}\text { - value attitude of an individual to his/her Homeland, } \\
\text { the motive of identity and a sense of belonging to the } \\
\text { Ukrainian nation; } \\
\text { - value attitude to the future profession, the desire for } \\
\text { professional self-realization; } \\
\text { - value attitude to oneself (self-concept, self-esteem); } \\
\text { - value attitude to interaction, communication with } \\
\text { other people on the basis of empathy as a form of } \\
\text { rational-emotional-intuitive reflection of another per- } \\
\text { son (according to V. Boyko). }\end{array}$ \\
\hline
\end{tabular}

son (according to V. Boyko)

\section{Cognitive-reflexive criterion:}

\section{Indicators:}

- knowledge of cultures and traditions of other peoples as well as building effective interaction with representatives of different nationalities and cultures;

- knowledge of the culture and traditions of the Ukrainian people;

- knowledge of the basic values of modern Ukrainian society;

- knowledge of the essence of patriotic values;

- knowledge of axiological aspects of the future profession;

- self-awareness of one's "I", self-esteem;

- knowledge about the inner world of other people and their attitude to themselves (communicative reflection);

- knowledge of the coordination of joint actions in a particular society (cooperative reflection).
Tolerance Index Express-questionnaire (G. Soldatova, O.

Kravtsova, O. Khukhlaev, L. Shaigerova), scale - ethnic tolerance.

Schwartz's Study of Personality Values Questionnaire, scale universalism.

Author's questionnaire on "The Level of Formation on Sociocultural Values According to the Motivational-axiological Criterion".

Author's questionnaire on "The Level of Formation of Sociocultural Values According to the Motivational-axiological Criterion".

"Value Orientations Study" Approach by P. Stepanov, scales: attitudes to culture, Homeland, spirituality.

"Study of Ethnic Identity" Approach (J. Phinney) - a scale of value components of ethnic identity (affective component).

Author's questionnaire on "The Level of Formation of Sociocultural Values According to the Motivational-axiological Criterion".

"Personal Professional Plan" Approach (by E. Klimov in the adaptation of L. Schneider).

"Value Orientations Study" Approach by P. Stepanov, scales: altruism-egoism, attitude to one's bodily self, attitude to one's inner world.

"Diagnosis of Interactive Personality Orientation" Approach (by N. Shchurkova modified by M. Fetiskin).

"Diagnosis of the Level of Empathic Abilities Approach by V. Boyko".

Method of independent expert assessments.

Author's questionnaire on "The Level of Formation of Sociocultural Values According to the Cognitive-reflexive Criterion".

Method of independent expert assessments.

Author's questionnaire on "The Level of Formation of Sociocultural Values According to the Cognitive-reflexive Criterion".

"Study of Ethnic Identity" Approach by J. Phinney - a scale of value components of ethnic identity (cognitive component).

Method of independent expert assessments.

Author's questionnaire on "The Level of Formation of Sociocultural Values According to the Cognitive-reflexive Criterion".

Intellectual reflection: "Study of Thinking Reflexivity" Approach (T. Pashukova and others); personal and cooperative reflection: methods of determining the level of reflection $(\mathrm{O}$. Anisimov); communicative reflection: methods of determining the level of reflexivity (A. Karpov, V. Ponomareva).

S. Budassi's Self-assessment of Personality Approach (modified version for studying professionally important qualities by O. Nemolot, S. Zubova). 
Continuation of Table 1

\begin{tabular}{|c|c|}
\hline 1 & 2 \\
\hline $\begin{array}{l}\text { Subject-activity criterion: } \\
\text { Indicators: } \\
\text { - experience, based on the implementation of socio- } \\
\text { cultural values; } \\
\text { - willingness to communicate and interact with rep- } \\
\text { resentatives of other nationalities; }\end{array}$ & $\begin{array}{l}\text { Author's questionnaire on "The Level of Formation of } \\
\text { Sociocultural Values According to the Subject-activity } \\
\text { Criterion". } \\
\text { Method of independent expert assessments. } \\
\text { "Schwartz's Study of Personality Values" Questionnaire, } \\
\text { scale - universalism. }\end{array}$ \\
\hline $\begin{array}{l}\text { - ability to organize their activities in accordance } \\
\text { with the basic values of modern Ukrainian society; }\end{array}$ & $\begin{array}{l}\text { Author's questionnaire on "The Level of Formation of Soci- } \\
\text { ocultural Values According to the Subject-activity Criterion". } \\
\text { Method of independent expert assessments. } \\
\text { "Assessment of Intensity of the Activity Component of Na- } \\
\text { tional Identity" Questionnaire by V. Borisov. }\end{array}$ \\
\hline $\begin{array}{l}\text { - activities for the benefit of Homeland on the basis } \\
\text { of patriotic values; } \\
\text { - realization of the value attitude to the future profes- } \\
\text { sion in the educational process of HEI; } \\
\text { - ability to self-analyze one's own value sphere, one's } \\
\text { actions and attitudes; } \\
\text { - ability to analyze the inner world of "others", their } \\
\text { attitude to themselves from the standpoint of value } \\
\text { experience; } \\
\text { - ability to build partnerships with other people on } \\
\text { the basis of "subject-subject interaction". }\end{array}$ & $\begin{array}{l}\text { Author's questionnaire on "The Level of Formation of } \\
\text { Sociocultural Values According to the Subject-activity } \\
\text { Criterion". } \\
\text { Method of independent expert assessments. } \\
\text { "K. Zamfir's Professional Activity Motivation" Approach (in } \\
\text { modification of A. Rean). } \\
\text { Questionnaire on "Level of Development of Personality } \\
\text { Subjectivity" (M. Shchukina). }\end{array}$ \\
\hline
\end{tabular}

The general sequence of the experimental work resolved itself to the following logical scheme:

1) diagnose the level of formation of sociocultural values of the respondents;

2) introduce the method of formation of students' sociocultural values to the educational environment of HEI;

3 ) show the dynamics of the formation of sociocultural values at different stages of their axiogenesis and environment formation.

It is important to note, that the specifics of the study determined the feasibility of parallel diagnostic and shaping work. The introduction of the methodology of formation of sociocultural values took place during the whole period of students' education in HEI, which provided for diagnostic monitoring.

The initial examination of students at the stage of the observational experiment took place at the beginning of education in HEI (1st year of study) and coincided with the first stage of axiogenesis and environment formation, which is characterized by acceptance and appropriation of values and models of axio-oriented behavior and entry into the new educational environment, adaptation and acceptance of its norms, when the student is still its object and occupies the "position of the performer", but the state of presence in an axio-oriented environment is formed, the immersiveness and interactivity of which are still limited.

The next stage of the experimental work was related to the current diagnosis of the level of formation of sociocultural values, when the obtained results were compared with the primary ones. There was a further introduction of the methods of formation of sociocultural values. This stage of the experimental work (II, III year of study in HEI) coincided with the second stage of axiogenesis, characterized by awareness and internalization of sociocultural values, as well as active reproduction by students of the educational environment, when their relationships become "intersubjective" in the conditions of increasing interactivity and personalization of the environment.

The next stage of the experimental study (IV year of study in the HEI) was defined as a control and involved the final diagnosis and analytical processing of the results. This stage corresponded to the third stage of axiogenesis, the content of which was the emergence of stable (system of values, meanings) values; the active influence on the environment were taking place; that is the student was already a "polysubject", "metasubject" of the environment; his/her "fixation", increased immersiveness, presence, interactivity were rising.

\section{Conclusions}

1. The presented article reveals the criteria and diagnostic tools of the experimental research, clarifies the directions and objects of verification of the effectiveness of methods of forming sociocultural values of students, identifies the stages of the experimental work that reflect the logic of diagnostic monitoring of formation of sociocultural values, their axiogenesis and stages of axiooriented environment formation.

2. In general, the logic of the experimental work was resolved to the following scheme: 1) diagnosis of the level of formation of sociocultural values; 2) introduction of methods of formation of sociocultural values of students in the educational environment of HEI; 3) analysis of the dynamics of sociocultural values development at different stages of their axiogenesis and environment formation.

3. The analysis of the results of the control section showed positive changes in the levels of formation of sociocultural values of the students of the experimental 
group in comparison with the control group. The increase in the level of formation of sociocultural values was established according to the following criteria: according to the motivational-axiological criterion, the number of students with a high level increased in EG by $43.49 \%$, in CG by $2.92 \%$; according to the cognitive-reflexive criterion - in EG by $49.81 \%$, in CG by $20.85 \%$; according to the subject-activity criterion - in EG by $41.67 \%$, in CG by $0.25 \%$. However, within this article it is not possible to disclose all aspects of the experimental component of the study. We believe that the analysis of the sample of students, who participated in the experiment, as well as the presentation of the results of statistical processing of experimental materials require further development.

\section{References}

1. Zimnyaya, I. A. (2010). Pedagogicheskaya psikhologiya. Moscow: Moscow Psychological and Social Institute. Voronezh: NPO MODEK, 448 .

2. Vygotsky, L. S.; Shtutina, L. M., Malova, L. M. (Eds.) (1999). Pedagogicheskaya psikhologiya. Moscow: Pedagogyprogress, 536

3. Leontiev, D. A. (1996). Ot sotsialnykh tsennostey k lichnostnym: sotsiogenez i fenomenologiya tsennostnoy regulyatsii deyatelnosti. Moscow University Bulletin. Series 14, Psychology, 4, 35-44.

4. Severina, T. (2013). Stanovlennya aksiosfery maybutnykh fakhivtsiv v vyshchomu navchalnomu zakladi. Problemy pidhotovky suchasnoho vchytelya, 7, 198-204.

5. Mitsko, V. M. (2014). Tsinnisno-smyslova sfera osobystosti studenta: teoretychnyy aspekt. Scientific notes of the National University "Ostroh Academy". Series: Psychology and Pedagogy, 27, 84-87. $138-150$.

6. Radchuk, G. (2012). Psychological principles of professional axiogenesis of personality. Personality Psychology, 1 (3),

7. Schwartz, S. (2008). Cultural value orientations: the nature and consequences of national differences. Psychology. Journal of the Higher School of Economics, 2 (5), 37-67.

8. Yanytskyy, M. S., Seryy, A. V., Pelekh, Yu. V. (2011). Diagnosis of the level of development of the value-semantic sphere of personality. Rivne: MEHU, 284.

9. Zaredinova, E. (2018). The students' social and cultural values formation model in the educational environment of a higher education institution. Theoretical and Methodical Problems of Children and Youth Education, 22, 90-101. doi: http://doi.org/10.32405/2308-37782018-22-90-101

10. Bespalko, V. P. (2012). Elementy teorii upravleniya protsessom obucheniya. Part 2 (Izmereniye kachestva protsessa obucheniya). Moscow: Knowledge, 72.

Received date 14.10.2020

Accepted date 23.11.2020

Published date 25.12.2020

Elvira Zaredinova, PhD, Associate Professor, Senior Researcher, Laboratory of Moral Civic and Intercultural Education, Institute of Educational Problems National Academy of Pedagogical Sciences of Ukraine, M. Berlinskoho str., 9, Kyiv, Ukraine, 04060

E-mail: zaredinova.elvira@gmail.com 